\title{
Age Based Relationships among Loneliness, Pet Attachment Support, Wellbeing and Quality of Life in Pet Owners: A Socio-Emotional and Neurological Rehabilitation Perspective
}

\author{
Hafsa Shams ${ }^{1}$, Shahnaz Kausar Yousaf ${ }^{2}$, Fusha Ishrat ${ }^{1}$, Umme Kulsoom $^{1}$, Shahrukh Mehtab ${ }^{3}$, \\ Gul Zaman ${ }^{4}$, Abdul Ghafoor Sajjad ${ }^{5}$ and Mubin Mustafa Kiyani6* \\ ${ }^{1}$ Foundation university Islamabad, Pakistan \\ ${ }^{2}$ Fauji Foundation Hospital Rawalpindi, Pakistan \\ ${ }^{3}$ Shaheed Zulfiqar Ali Bhutto Medical University, Pakistan \\ ${ }^{4}$ International Committee of the Red Cross, Pakistan \\ ${ }^{5}$ Department of Rehabilitation Sciences, Shifa Tameer-e-Millat University, Pakistan \\ ${ }^{6}$ Shifa College of Medical Technology, Shifa Tameer-e-Millat University, Pakistan \\ *Corresponding author: Mubin Mustafa Kiyani, Shifa College of Medical Technology, Shifa Tameer-e-Millat University, Pakistan
}

\section{ARTICLE INFO}

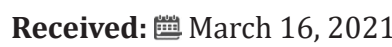

Published: 慧 March 24, 2021

Citation: Hafsa Shams, Shahnaz Kausar Yousaf, Fusha Ishrat, Umme Kulsoom, Mubin Mustafa Kiyani, et al., Age Based Relationships among Loneliness, Pet Attachment Support, Wellbeing and Quality of Life in Pet Owners: A Socio-Emotional and Neurological Rehabilitation Perspective. Biomed J Sci \& Tech Res 34(4)-2021. BJSTR. MS.ID.005598.

Keywords: Age; Pet Attachment; Gender Differences

\section{ABSTRACT}

Background: Children's social, emotional, and cognitive development, as well as their mental wellbeing and quality of life, are all affected by their pet attachment. Animals and humans have lived side by side for thousands of years. Although the majority of these relationships benefited humans, a limited number of them benefited animals. Attachments, including those between humans and their pets, provide a specific and open source of social support, according to theorists.

Objective: The purpose of this study was to examine the relationship between age and pet attachment in individuals and to find out the gender differences

Methods: It was a cross sectional descriptive study. Data was collected from participants $(n=200)$ including both males and females ranging from age thirteen to sixty four from Abbottabad, Islamabad and Rawalpindi. Data was analyzed using SPSS 20 version. A correlational and t test analysis was run between the total scores on the Lexington Attachment to Pets Scale.

Results: Results obtained from this study indicated that there is a significant positive relationship between age and pet attachment whereas, there is no major gender differences found in the population of Pakistan.

Conclusion: There was a significant positive relationship between age and pet attachment whereas, there is no major gender differences found in the population of Pakistan.

\section{Introduction}

Pets have been an important part of human life throughout history, independent of culture [1]. For thousands of years, animals and humans have coexisted. While most of these relationships benefited humans, a minority of them offered survival advantages for animals. The relationship between humans and animals may be as old as 32,000 years, and it remains true even today. The majority of households have at least one pet, with up to $65 \%$ of these containing a dog or cat [2]. Many people would say that having a 
pet fulfils the need for warmth and reassurance, help, and security [3]. Research shows that humans and their pets can develop strong attachments to each other, and some pets have demonstrated attachment behaviors toward their human caretakers. There are occasions where these relationships have been shown to increase the physical and emotional well-being of both species [4]. The roots of attachment theory are found in ethology, where the study of evolutionary and biological concepts are concerned with the nature of mother-offspring relationships. In order for offspring to obtain food, warmth, shelter, and other services during a particularly vulnerable time of life, attachment served as a mechanism that allowed them to locate their caregiver [5].

When humans are in need, animals can provide compassion, pleasure, and affection, and they respond with unconditional love [6]. People who are deeply attached to their pets, their pets are treated as members of their family [7]. Having an animal can provide socialization and security for the owner. To claim that an animal is a pet means that a person has developed a bond with it, which offers both psychological and social support [8]. The existence of dogs in urban areas and family homes is becoming increasingly popular throughout the world [9]. The characteristics of the pet owner, such as age, gender, income/social class, marital status, rural/urban residence and household type, have been shown to be associated with the number of pets owned [10]. Attachment figures as defined by four features. Their physical proximity and accessibility are enjoyable (proximity maintenance); they are missed when absent (separation distress); they are reliable sources of comfort (secure base); and they are intended to relieve distress (safe haven) [11].

The term attachment in people is often characterized by reference to Bowlby's (1969) theory, which considers attachment to be a deep and long-lasting emotional connection that binds one person to another through space and time [12]. Society is increasingly accepting service animals as beneficial to our welfare, and many owners regard them as sincere and affectionate family members. The relational and supportive dimensions of the humancompanion animal connection are best understood with the aid of human relationship theories [13]. The study investigated the role of pet attachment in individuals with respect to age and the level of attachment in males and females. The contact with the animal may also directly and positively influence the physiological state of the human being, which is linked to releases at the owner's oxytocin

Table 1: Pearson Product Correlation between age and pet attachment of the individuals $(\mathrm{N}=200)$.

\begin{tabular}{|c|c|c|c|}
\hline S.no & Variables & $\mathbf{1}$ & \\
\hline 1 & Age & $.18^{*}$ & \\
\hline 2 & Pet Attachment & - & - \\
\hline
\end{tabular}

Note: ${ }^{*} \mathrm{p}<.05$ emphasizes the impact of Age in pet owners on their behavioral and social aspects like age related loneliness, their attachments with their pets, wellbeing and Quality of life and neurological recreational roles of pets in old age pet owners.

\section{Method}

A total of 200 individuals were taken in this present study. Participants were pet owners (pets include dog, cat, fishes and birds), aged between 13 and 64 years. Among them 100 were female and 100 male participants. Data was collected from Abbottabad, Islamabad and Rawalpindi. For the purpose of data collection convenient sampling technique was used and research was conducted using cross sectional design. The Lexington Attachment to Pets Scale, LAPS [15] with certain modifications was used as measure in the study. LAPS is a 23 item scale, and each item is rated on a 5 point Likert scale from 1 to 5 ( 1 = agree strongly, 2 = agree somewhat, 3 = disagree somewhat, $4=$ disagree strongly and 5 = don't know or refuse) [15]. It was a cross sectional study design and the method used for collection of data was convenient sampling. Informed consent has being taken from the participants. Participants were informed about the nature of study and assured that data collected will only be used for research purpose. The results in this study were analyzed by performing data analysis using SPSS version 20 in which demographics frequencies were calculated, and correlation was checked, of pet attachment with age by using Pearson Product Moment correlation analysis. And to test the gender differences in level of pet attachment, t-test analysis was used.

\section{Results}

100 males and 100 females participated in this study. Pets were divided into two categories that is, animals and birds given in (Figure 1). The age of participants is given in (Figure 2). The number of animals owned by participants was 178 (89.0\%) and number of birds was 22 (11.0\%). Cronbach's alpha reliability of LAPS (Lexington Attachment to Pets Scale) indicates that items of the scale used are internally consistent to assess pet attachment in individuals. Result indicates there is a weak significant positive correlation between age and pet attachment (Table 1). The mean difference for pet attachment among male and females shows no significant differences $(p=.31)$ among males and females on the scale of pet attachment (Table 2). level when their pets look at them [14]. In this study the authors 
Table 2: Mean difference for pet attachment.

\begin{tabular}{|c|c|c|c|c|c|c|c|c|c|c|}
\hline \multirow{2}{*}{ Variable } & \multirow{2}{*}{ Gender } & \multirow{2}{*}{$\mathbf{n}$} & \multirow{2}{*}{$\mathbf{M}$} & \multirow{2}{*}{ SD } & \multirow{2}{*}{$\mathbf{t}$} & \multirow{2}{*}{$\mathbf{p}$} & \multirow{2}{*}{$\begin{array}{c}\text { Std Error } \\
\text { Mean }\end{array}$} & \multirow{2}{*}{ Cohen's d } & \multicolumn{2}{|c|}{$95 \%$ CI } \\
\hline & & & & & & & & & LL & UL \\
\hline \multirow{2}{*}{ LAPS Total } & Male & 100 & 44.9 & 9.67 & 1.01 & .31 & 0.97 & .14 & -1.34 & 4.19 \\
\hline & Female & 100 & 43.5 & 10.16 & 1.01 & .31 & 1.02 & .14 & -1.34 & 4.19 \\
\hline
\end{tabular}

Note: $\mathrm{df}=198$

CI: Confidence Interval; LL: Lower Limit; UL: Upper Limit

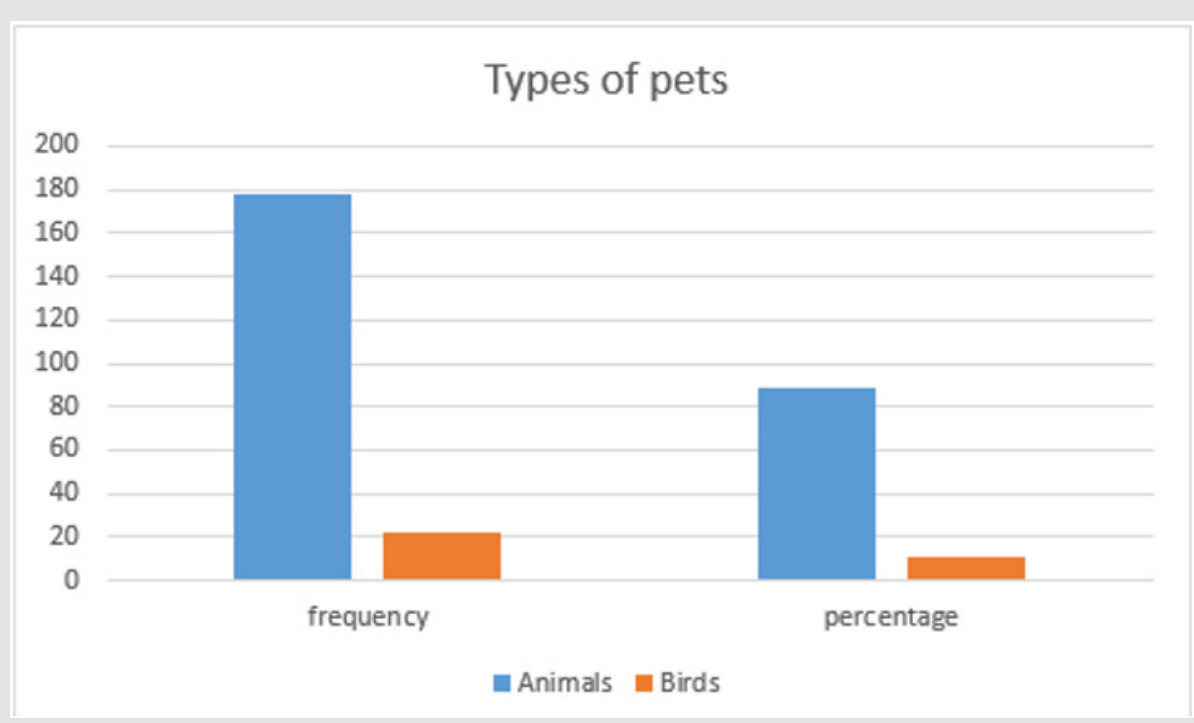

Figure 1: Bar chart of frequency of types of pets.

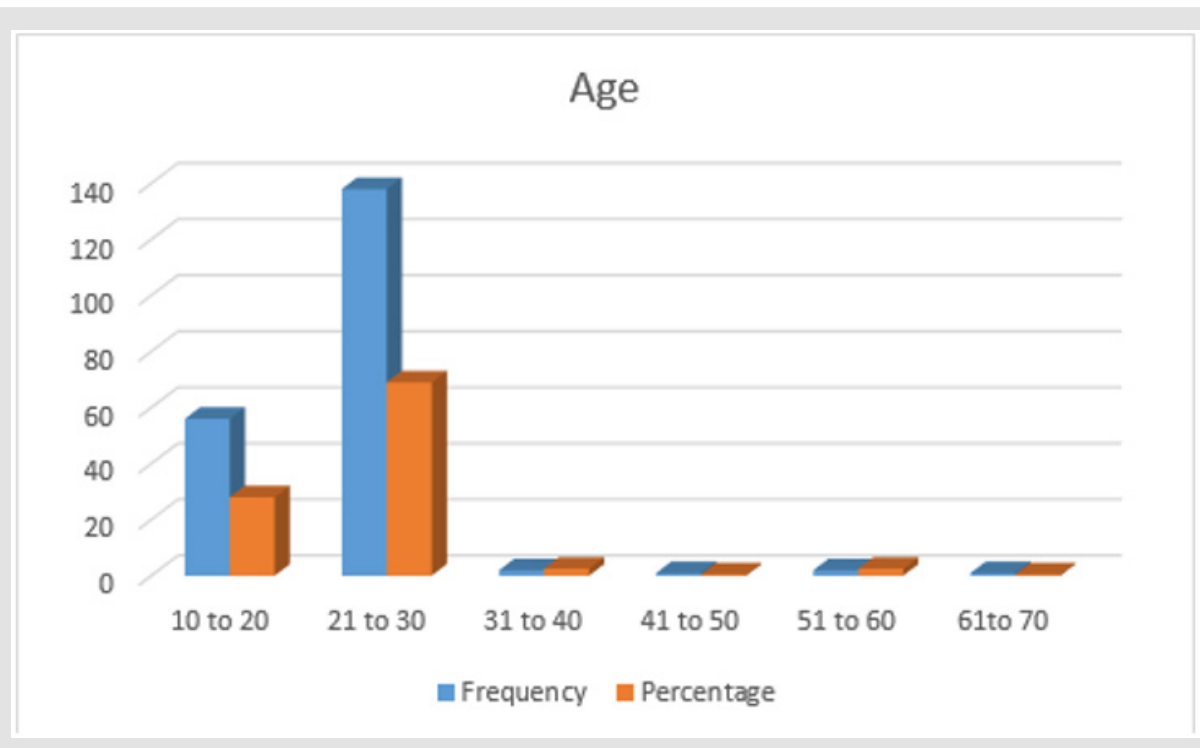

Figure 2: Bar chart of frequency of Age of participants.

\section{Discussion}

The present study was designed to investigate the relationship of age with pet attachment and also find out whether there is any gender differences present in level of pet attachment. The sample of study comprised of 200 participants constituting males and females. Pet attachment was measured by using The Lexington Attachment to Pets Scale, LAPS was developed by Johnson, et al. [15]. The first hypothesis of the study was to find relationship of pet attachment with age. It was hypothesized that pet attachment has a positive relationship with age. Cronbach's alpha reliability of LAPS (Lexington Attachment to Pets Scale) is 0.82 which indicates 
that items of the scale used are internally consistent to assess pet attachment in individuals. The first hypothesis of the study was to find relationship of pet attachment with age. It was hypothesized that pet attachment has a positive relationship with age. Findings through Pearson Product correlation indicated that there exists a significant weak positive relationship $(r=.18, \mathrm{p}<.05)$ of pet attachment with age.

The results show weak but significant correlation between the two. This suggests that with aged people are more attached to their pets. It supports the hypothesis of this present study that pet attachment is positively linked with age. Previous studies have shown the same results on the relationship between pet attachment and age. In a study conducted by Goldmeier [16], who carried out a correlation study that showed that older women living with pets were less lonely, more optimistic and more interested in making plans for the future, as well as less nervous compared to women living alone [16]. Finding through t-test analysis indicate that there are no differences in level of pet attachment among males and females $(t=.31, p<.05)$. The results show no significant differences among males and females on the scale of pet attachment. Results don't support the hypothesis of this present study. Many studies show that people have strong affectionate ties with their dogs, treating them as family members or children.

The present study investigates differences between female and male owners during interactions with their dogs, in a situation designed to investigate attachment and thus to promote emotional and emotional reactions: Ainsworth's Strange Situation. Twentyfive owners of dogs, 10 men and 15 women, were observed during free interactions with their pets in an adapted version of the 'strange situation procedure.' Their behavior towards their pets has been recorded in video. There were no clear gender differences in affiliation and play behavior. Both women and men engaged in dog play and provided physical comfort. There were no differences in the level of attachment reported by women and men in the questionnaire [17].

\section{Conclusion}

This study was conducted with an aim to see the relationship of pet attachment with age and also to find gender differences in level of pet attachment. From the above mentioned literature, results and discussion, it is suggested that there exist a weak significant positive relationship of pet attachment with age; also, there are no significant gender differences present in level of pet attachment. Result indicates a positive relation of pet attachment with age.

\section{References}

1. Wong K (2013) Scrappy pets. Scientific American 308(4): 24.

2. Mornement K (2018) Animals as companions. In Animals and human society. Academic Press, pp. 281-304.

3. Zilcha Mano S, Mikulincer M, Shaver PR (2012) Pets as safe havens and secure bases: The moderating role of pet attachment orientations. Journal of Research in Personality 46(5): 571-580.

4. Wanser SH, Vitale KR, Thielke LE, Brubaker L, Udell MA (2019) Spotlight on the psychological basis of childhood pet attachment and its implications. Psychology research and behavior management 12: 469479.

5. The origins of attachment theory developed within ethology, with a focus on the evolutionary and biological foundations of motheroffspring relationships. The function of attachment, as a mechanism by which offspring came to seek out the proximity of their caretaker provided opportunities for offspring to obtain food, warmth, shelter, and other resources during an especially vulnerable period of life.

6. Walsh F (2009) Human-Animal bonds II: The role of pets in family systems and family therapy. Family process 48(4): 481-499.

7. Cohen SP (2002) Can pets function as family members?. Western Journal of Nursing Research 24(6): 621-638.

8. Horowitz S (2008) The human-animal bond: Health implications across the lifespan. Alternative \& Complementary Therapies 14(5): 251-256.

9. Volsche S, Mohan M, Gray PB, Rangaswamy M (2019) An exploration of attitudes toward dogs among college students in Bangalore, India. Animals 9(8): 514.

10. Martins CM, Mohamed A, Guimarães AM, De Barros CD, Dos Santos Pampuch R, et al. (2013) Impact of demographic characteristics in pet ownership: modeling animal count according to owners income and age. Preventive veterinary medicine 109(3-4): 213-218.

11. Ainsworth MD (1991) Attachments and other affectional bonds across the life cycle. Attachment across the life cycle 5: 122-164.

12. Marsa Sambola F, Muldoon J, Williams J, Lawrence A, Connor M, et al. (2016) The short attachment to pets scale (SAPS) for children and young people: Development, psychometric qualities and demographic and health associations. Child Indicators Research 9(1): 111-131.

13. Meehan M, Massavelli B, Pachana N (2017) Using attachment theory and social support theory to examine and measure pets as sources of social support and attachment figures. Anthrozoös 30(2): 273-289.

14. Nagasawa M, Mogi K, Kikusui T (2009) Attachment between humans and dogs. Japanese Psychological Research 51(3): 209-221.

15. Johnson TP, Garrity TF, Stallones L (1992) Psychometric evaluation of the Lexington attachment to pets scale (LAPS). Anthrozoös 5(3): 160175 .

16. Goldmeier J (1986) Pets or people: Another research note. The Gerontologist 26(2): 203-206.

17. Prato Previde E, Fallani G, Valsecchi P (2006) Gender differences in owners interacting with pet dogs: an observational study. Ethology 112(1): 64-73. 
ISSN: 2574-1241

DOI: 10.26717/BJSTR.2021.34.005598

Mubin Mustafa Kiyani. Biomed J Sci \& Tech Res

(C) This work is licensed under Creative

Submission Link: https://biomedres.us/submit-manuscript.php

$\begin{array}{ll}\text { BIOMEDICAL } & \text { Assets of Publishing with us } \\ \text { RESEARCHES } & \text { - Global archiving of articles } \\ \text { - Immediate, unrestricted online access } & \text { - Rigorous Peer Review Process } \\ & \text { - Authors Retain Copyrights }\end{array}$

